\title{
Hot-water-extracts of Polygonum Multiflorum Do Not Induce Any Toxicity but Elicit Limited Beneficial Effects on the Liver in Mice
}

\author{
Toshihiro Noda,${ }^{a}$ Takehiro Yamada, ${ }^{a}$ Tomoko Ohkubo, ${ }^{a}$ Tomohiro Omura, ${ }^{a}$ \\ Takashi Ono ${ }^{a}{ }^{\text {Tomoki Adachi, }}{ }^{a}$ Toshio Awaya, ${ }^{a}$ Yoshikazu Tasaki, ${ }^{a}$ Keiko Shimizu, ${ }^{b}$ \\ and Kazuo Matsubara*, $a$
}

${ }^{a}$ Department of Hospital Pharmacy and Pharmacology and ${ }^{b}$ Department of Legal Medicine, Asahikawa Medical College, 2-1-1-1 Midorigaoka-Higashi, Asahikawa, Hokkaido 078-8510, Japan

(Received February 25, 2009; Accepted August 4, 2009; Published online August 7, 2009)

\begin{abstract}
Shou-Wu-Pian, a herbal remedy formulated from Polygonum multiflorum (PM), has been extensively used for the treatment of hair-loss, constipation and vertigo in Asia, Europe and U.S.A. Although recent reports have indicated severe liver damage occurred after taking Shou-Wu-Pian in humans, studies on the hepatotoxicity of this herbal remedy have been limited, and this organ-specific adverse effect induced by PM intake remains to be confirmed. In this study, hepatotoxicity of hot-water-extracted PM was investigated in vitro and in vivo in mice. After treating primary cultured hepatocytes with PM extracts at 3 final concentrations $(0.5,1$ and $5 \mathrm{mg} / \mathrm{ml})$ with or without acetaminophen $(10 \mathrm{mM})$ for $24 \mathrm{hr}$, no cytotoxic effects were observed. In fact, cell viability and lactate dehydrogenase leakage were significantly improved at the highest PM extracts dose compared with controls. Mice orally administered twice daily with the PM extracts $(20$ or $340 \mathrm{mg}$ extracts/mouse $\times 2)$ for 10 days indicated no unfavorable effect on the liver function. Only when mice subchronically received the higher dose of the PM extracts $(340 \mathrm{mg})$ before treatment with a single-bolus dose of acetaminophen $(500 \mathrm{mg} / \mathrm{kg}$; i.p.), attenuation of acetaminophen-induced hepatotoxicity was significantly established in vivo. The results in the present study contradicted hepatotoxic findings reported in humans; PM extracts do not induce any toxicological effects, at least on the liver, and may in fact elicit useful but limited beneficial effects on the liver in vivo.
\end{abstract}

Key words — Polygonum multiflorum, herbal medicine, hepatocyte, acetaminophen, lactate dehydrogenase

\section{INTRODUCTION}

There is growing evidence that herbal medicines have multiple beneficial effects on human health maintenance. As a result of growing distrust in chemically synthesized compounds (modern therapeutics/medicines) and "on-line shops" on the internet, patients are taking note of alternative medicines/remedy and herbal products. Taking traditional Chinese medicines has always been perceived to be a safe remedy merely because these preparations are accepted as "natural products." However, reports of adverse reactions elicited by these so-called "natural products" have been increasing since the $1990 \mathrm{s.}^{1-7)}$ In 2001 , a

\footnotetext{
*To whom correspondence should be addressed: Department of Hospital Pharmacy and Pharmacology, Asahikawa Medical College, 2-1-1-1 Midorigaoka-Higashi, Asahikawa, Hokkaido 078-8518, Japan. Tel.: +81-166-69-3480; Fax: +81166-65-1392; E-mail: kmatsuba@asahikawa-med.ac.jp
}

woman who took a herbal medicine/product derived from Polygonum multiflorum (PM) showed acute hepatitis-like symptoms with marked increases of serum alanine aminotransferase (ALT) to as high as $900 \mathrm{U} / \mathrm{l}^{1)}$ More recently, 2 cases with hepatotoxicity supposedly caused by taking PM products have been documented. ${ }^{3)}$ As a consequence, caution on the intake of PM preparations have been heeded in "herbal safety news and food safety information" by the British and Japanese governments in April $^{8)}$ and $\mathrm{May}^{9)}$ of 2006, respectively. However, hepatotoxic effects of the herbal product remain unclear as experimental and clinical studies with regulated and strict controls have not been attempted to date. In contrast to these unfavorable reports on humans, PM extracts have been reported to elicit various beneficial effects in experimental animals; ${ }^{10-13)}$ $v i z$. , the extracts promote hair growth in the hair-loss mouse model, ${ }^{10)}$ ameliorates behavioral abnormalities and biochemical parameters in the experimen- 
tal Alzheimer's disease model (induced by amyloid $\beta$-treatment ${ }^{12)}$ and attenuates carbon tetrachloride $\left(\mathrm{CCl}_{4}\right)$-induced liver dysfunction. ${ }^{13)}$

PM extracts may serve as a useful ingredient in herbal products, and it contains multivariate pharmacologically active principles, such as polyphenolic compounds, minerals and other organic/inorganic components. Although useful, variations in the content of these pharmacologically active components yield complications and repercussions in the evaluation of herbal medicines incorporating PM extracts. Thus, elaborate in vitro and in vivo experiments are warranted to evaluate toxic and benefic effects of PM extract-incorporated herbal medicines. As direct in vitro and in vivo effects on hepatocytes and the intact liver have not been respectively attempted, we therefore elucidated the effects of hot-water PM extracts on hepatic functions using primary-cultured hepatocytes in vitro and the acetaminophen-induced liver injury model in vivo in mice.

\section{MATERIALS AND METHODS}

Animals — Male ICR mice (age: 7 to 10 weeks, body weight: 25-35 g; SLC, Shizuoka, Japan) accommodated in an air-conditioned room under an alternating 12-hr light-dark illumination cycle were given feed and drinking water ad libitum. Experimental studies were conducted according to the "Guidelines for care and use of laboratory animals" stipulated by the Ethical Committee of Asahikawa Medical College.

Reagents — PM (Tochimoto Tenkaido Co. Ltd., Osaka, Japan), William's medium E, fetal calf serum (FCS), L-glutamine (GIBCO, Carlsbad, CA, U.S.A.), fetal bovine serum (Tissue Culture Biologicals, Tulare, CA, U.S.A.), collagenase type II (Worthington Biochemical Co., Lakewood, NJ, U.S.A.), acetaminophen, penicillin-streptomycin (Sigma, St. Louis, MO, U.S.A.) and other chemicals (Wako Pure Chemicals, Osaka, Japan) used in the experiments were either of the highest or analytical grade.

Preparation of PM Extracts — PM (5 g or $85 \mathrm{~g}$ ) was submerged in $300 \mathrm{ml}$ of distilled water, and the mixture was boiled under reflux for $c a$. $2 \mathrm{hr}$ until the water volume was concentrated to $50 \mathrm{ml}(100$ or $1700 \mathrm{mg} / \mathrm{ml}$ extracts, respectively). The concentrate (clear brown solution) was sterilized by PVDFmembrane filtration (pore size; $0.45 \mathrm{~mm}$, Millipore,
Billerica, MA, U.S.A.). The collected extracts were kept at $4^{\circ} \mathrm{C}$ and warmed up to $37^{\circ} \mathrm{C}$ just before use. In vitro Study Using Isolated Murine Hepatocytes — Isolated hepatocytes from male ICR mice were prepared by the collagenase perfusion method of Moldeus et al. ${ }^{14)}$ with slight modifications. Briefly, the surgically exposed liver of the ketamine/xylazine-anesthetized mouse was initially perfused with Hank's balanced solution (pH 7.4) supplemented with HEPES $(10 \mathrm{mM})$ and $\mathrm{NaHCO}_{3}$ $(4.16 \mathrm{mM})$ for $20 \mathrm{~min}$ (total volume: $150 \mathrm{ml}$ ) followed by Hank's balanced solution containing collagenase (321 units $/ \mathrm{ml}$ ) at a flow rate of $8 \mathrm{ml} / \mathrm{min}$ for 12 to $15 \mathrm{~min}$ (volume used: $100 \mathrm{ml}$ ). The isolated hepatocytes were washed twice with $20 \mathrm{ml}$ of phosphate buffered saline (PBS, pH 7.2) before centrifugation at $50 \times g$ at $4^{\circ} \mathrm{C}$ for $1 \mathrm{~min}$. The hepatocytes were then suspended in William's $\mathrm{E}$ medium containing $10 \%$ FCS $\left(2 \times 10^{5}\right.$ cells $\left./ \mathrm{ml}\right)$ before being seeded onto a collagen-coated 24- or 96-well plate at $1 \times 10^{4}$ cells $/ \mathrm{cm}^{2}$. Isolated hepatocytes were cultured in William's medium E containing $10 \%$ FCS, glutamine $(2 \mathrm{mM})$, penicillin $(100 \mathrm{U} / \mathrm{ml})$ and streptomycin $(0.1 \mathrm{mg} / \mathrm{ml})$ at $37^{\circ} \mathrm{C}$ for $6 \mathrm{hr}$. The trypan blue exclusion test revealed hepatocyte viability to have surpassed $90 \%$.

After rinsing, cells in the plates were treated with 3 different concentrations of the PM extracts (final concentrations: $0.5,1$ and $5 \mathrm{mg} / \mathrm{ml}$ extracts) with or without $10 \mathrm{mM}$ acetaminophen for $24 \mathrm{hr}$ in the culture medium containing $10 \%$ FCS or in the serum-free medium. Effects on the hepatocytes were monitored with the lactate dehydrogenase (LDH)-leakage into the culture medium from cells using the LDH-cytotoxic test (Wako Pure Chemicals), and cell viability was evaluated by the WST-8 test. ${ }^{15)}$

In vivo Effect of PM- Mice were orally administered an aliquot of the PM extracts (lower dose: $20 \mathrm{mg} / 0.2 \mathrm{ml} / \mathrm{mouse}$, higher dose: $340 \mathrm{mg} /$ $0.2 \mathrm{ml} /$ mouse) twice a day (10:00 and 16:00 hr) with a stomach tube for 10 consecutive days. Control mice were treated in a similar manner with oral intake of distilled water $(0.2 \mathrm{ml} /$ intake $)$ twice daily. Two hr after the final drug/vehicle administration on day 10 , mice were intraperitoneally administered with acetaminophen $(500 \mathrm{mg} / \mathrm{kg}$; dissolved in saline). Blood was sampled and relevant organs (i.e., liver, spleen, thymus, kidney) were extracted from mice under ether anesthesia $4 \mathrm{hr}$ after acetaminophen treatment. Plasma ALT, aspartate aminotransferase (AST), LDH and total bilirubin 
(T-Bil) levels were determined using a commercial kit (Transaminase C II-test, Wako Pure Chemicals) or determined by SRL laboratories (Tokyo, Japan) for liver functions.

Histopathological Study — After $12 \mathrm{hr}$ of fixing in $4 \%$ paraformaldehyde solution, liver tissue embedded in paraffin was cut into $4 \mu \mathrm{m}$ thick serial sections. The specimen was mounted on a glass slide and deparaffinized with graded concentrations of xylene and ethanol, and then stained with hematoxylin and eosin. The microscopic observation was examined under an Olympus BX50 photomicroscope (Olympus, Tokyo, Japan).

Statistical Analysis — All values expressed as the mean \pm S.E. were statistically verified by the one-factorial analysis of variance (ANOVA) method before the post-hoc Tukey's Multiple Comparison test. Differences where a $p$ value of $<0.05$ were considered statistically significant.

\section{RESULTS}

\section{Effects of the Hot-water PM Extracts on Cul- tured Murine Hepatocytes}

The amount of LDH leaked into the culture medium was designated as $100 \%$ when cells were treated with culture medium containing $1 \%$ Tween 20. Removal of serum from the culture medium resulted in cell damage; $20 \% \mathrm{LDH}$-leakage from the cell was subsequently observed (Fig. 1). From the in vitro findings based on LDH-leakage and cell viability (Figs. 1 and 2), the PM extracts did not induce any hepatotoxic effect in the primary cultured hepatocytes On the contrary, pretreatment with the highest amount of PM extracts significantly $(p<0.01)$ reduced the basal level of LDH-leakage (Fig. 1).

\section{In vitro Effects of the PM Extracts on Acetami- nophen-induced Hepatotoxicity}

Acetaminophen treatment induced significant $(p<0.001)$ hepatotoxicity (Fig. 1); i.e., LDHleakage into the culture media was $60 \%$ and $20 \%$ of total intracellular contents in the acetaminophentreated and control hepatocytes (Fig. 1). A similar cytotoxic tendency was observed in the cell viability assay, acetaminophen $(10 \mathrm{mM})$ treatment markedly $(p<0.01)$ killed $50 \%$ of hepatocytes compared with non-treated cells (Fig. 2).

Interestingly, co-incubation of hepatocytes with the PM extracts attenuated acetaminophen-induced

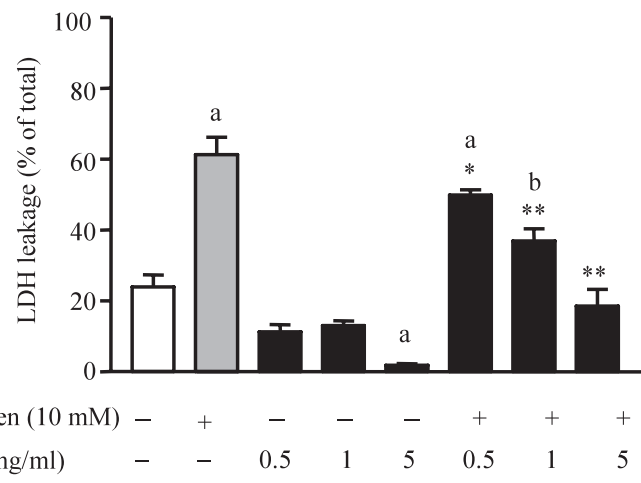

Fig. 1. Effect of the Hot-water-extracted PM on LDH-leakage in Primary-cultured Hepatocytes

Murine hepatocytes $\left(2 \times 10^{4}\right.$ cells/well $)$ were seeded onto collagen-coated 24-well plates and incubated with 10\% FCS for $6 \mathrm{hr}$ before being exposed and incubated with PM for another 24-hr interval. LDH-leakage, expressed as a percentage (\%) of the vehicle-treated cells, was used as an index for cytotoxicity. Treatments with (+) and without (-) acetaminophen or PM extract are indicated on the abscissa. Data represent the mean \pm S.E. of 4-7 analyses. Differences where $p<0.05\left(^{*}\right)$ or $<0.001\left(^{* *}\right)$ and those where $p<0.001\left(^{(a)}\right.$ or $<0.01\left({ }^{b}\right)$ were considered significant when compared with the acetaminophen (10 mM, shaded bar)- and vehicle-treated (open bar) groups, respectively.

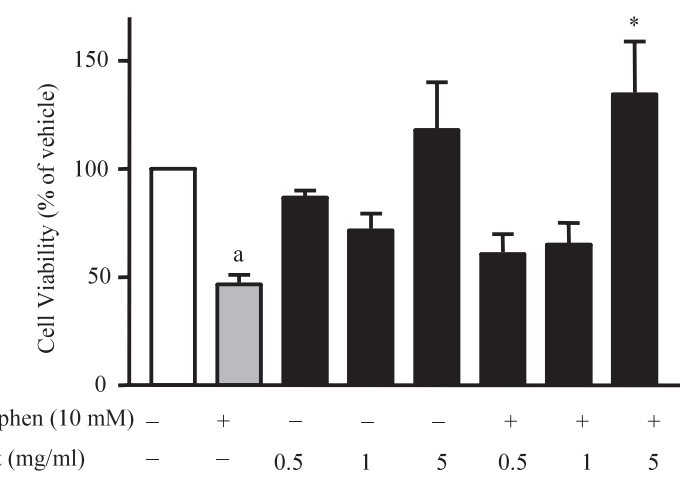

Fig. 2. Effects of the Hot-water-extracted PM on Cell Viability in Primary-cultured Murine Hepatocytes

Hepatocytes $\left(3.5 \times 10^{4}\right.$ cells/well) seeded onto 96 -well plates were incubated with $10 \%$ FCS for $6 \mathrm{hr}$ before being exposed to the PM extract for another 24-hr interval. Cell viability was assessed by measuring optical density at $450 \mathrm{~nm}$ with a microplate reader after 3-hr loading with WST-8. Treatment with (+) and without (-) acetaminophen or PM extract is indicated on the abscissa. Data represent the mean \pm S.E. of 3-5 analyses. Differences where $p<0.001\left(^{\mathrm{a}}\right)$ or $<0.05\left(^{*}\right)$ were considered significant when compared with the vehicle (open bar)- or the acetaminophen $(10 \mathrm{mM}$, shaded bar)-treated group, respectively.

hepatotoxicity in a dose-dependent manner (Fig. 1). At the highest $(5 \mathrm{mg} / \mathrm{ml})$ dose, treatment with the PM extracts completely attenuated acetaminopheninduced LDH-leakage in hepatocytes $(p<0.01$, Fig. 1) and significantly prevented acetaminopheninduced cell death $(p<0.01$, Fig. 2). 


\section{In vivo Evaluation of the PM Extracts on Aceta- minophen-induced Acute Hepatotoxicity}

The subchronic PM treatment (both lower and higher doses) did not affect organ/tissue weights or hematological parameters (red blood cell/white blood cell and platelet counts, mean corpuscular volume, hemoglobin content, mean cell hemoglobin and mean corpuscular hemoglobin concentrations) in treated mice compared with those in controls (data not shown) as well as plasma markers of hepatic function (Fig. 3). The behavioral abnormality was not observed during and after the treatment with PM extracts. A single-bolus administration of acetaminophen $(500 \mathrm{mg} / \mathrm{kg})$-induced acute hepatotoxicity assessed by plasma ALT, AST, LDH and T-Bil levels (Fig. 3). The 10-day consecutive pretreatment of the PM extracts attenuated the acetaminophen-induced hepatotoxicity, albeit the lower dose of PM extract did not show significant differences (Fig. 3).

Histopathological study revealed that the treatment with acetaminophen caused marked hepatic cell loss, especially around central veins, and erythrocyte leakage (Fig. $4 \mathrm{~B}$ ). The pretreatment (10 days) of higher dosage of PM extract dramatically attenuated acetaminophen toxicity (Fig. 4D), although the lower dosage was ineffective (Fig. 4 C).

\section{DISCUSSION}

Several reports have described severe hepatic dysfunctions caused by the intake of PM products in humans; ${ }^{1-3)}$ however, in vitro and in vivo findings in the present study showed protective effects. As far as we know, this is the first study that has demonstrated the non-cytotoxic effects of PM extract on primary cultured hepatocytes when monitored by cell viability. Additionally, the subchronic (10-day) PM pretreatment (a daily dose: 40 or $380 \mathrm{mg} / \mathrm{mouse}$ ) did not affect the hepatic function in mice when evaluated by plasma markers of hepatic function and other hematological parameters. A daily dose of $40 \mathrm{mg}$ extract intake (ca., $1.3 \mathrm{~g} / \mathrm{kg}$ ) in a mouse equals $80 \mathrm{~g}$ PM extract intake per day for a 60-kg human individual, while the recommended daily dose of PM for humans is $3-6 \mathrm{~g}$. These results provided essential important information for the consumers that the use of PM products within the recommended dose range could be potentially safe, at least for the liver, without any medical consultation with a physician, although consideration of the species difference in PM metabolism/response between humans and mice might have to be taken into account to a certain extent. The previously reported adverse events in humans ${ }^{1-3)}$ might have been due to possible contamination from other sources in
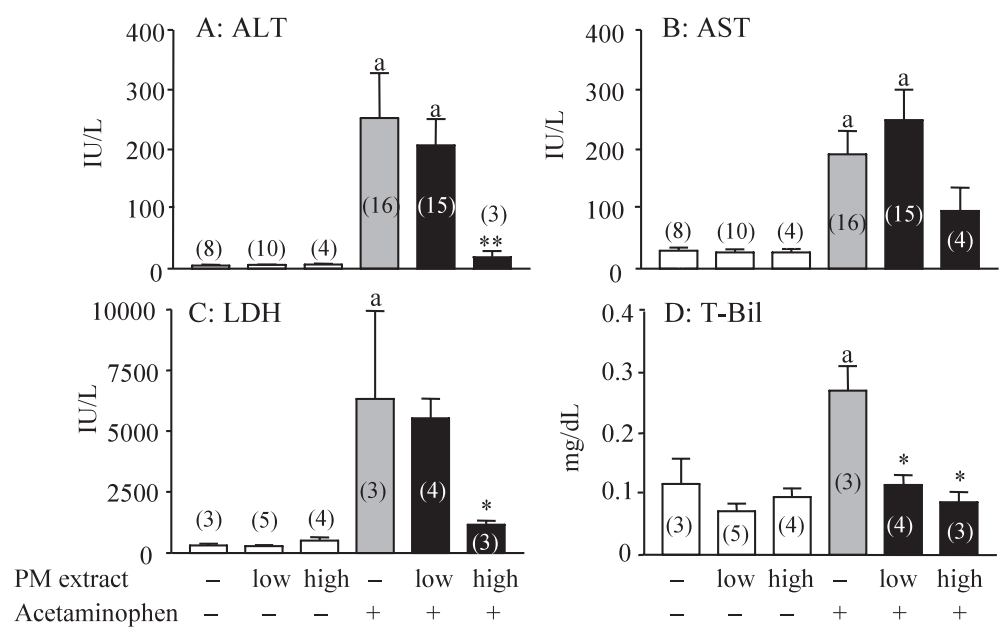

Fig. 3. Effects of Sub-chronic Treatment with PM Extracts on Liver Function in Mice

Mice were orally pretreated with hot-water-extracted PM (lower dose: $20 \mathrm{mg} / 0.2 \mathrm{ml} / \mathrm{mouse}$, higher dose: $340 \mathrm{mg} / 0.2 \mathrm{ml} / \mathrm{mouse}$ ) twice a day for 10 consecutive days, while control animals were similarly treated with distilled water $(2 \times 0.2 \mathrm{ml}$ per day). On day (final) 10, acetaminophen $(500 \mathrm{mg} / \mathrm{kg})$ was injected intraperitoneally in mice $2 \mathrm{hr}$ after the last oral administration of PM extract. Blood samples were drawn from ether-anesthetized mice by cardiac puncture $4 \mathrm{hr}$ after acetaminophen injection. Plasma ALT (A), AST (B), LDH (C) and T-Bil (D) levels were assessed for the liver function. Treatments with $(+)$ and without $(-)$ acetaminophen or PM extracts are indicated on the abscissa. Each value represents the mean \pm S.E. The number of experimental mice used is given in the parentheses. Each value represents the mean \pm S.E. Differences where $p<0.05\left({ }^{*}\right)$ or $<0.01\left(^{* *}\right)$ and those where $p<0.001\left({ }^{a}\right)$ were considered significant when compared with the acetaminophen-treated $(10 \mathrm{mM}$, shaded bar)- and corresponding PM (without acetaminophen) groups, respectively. 

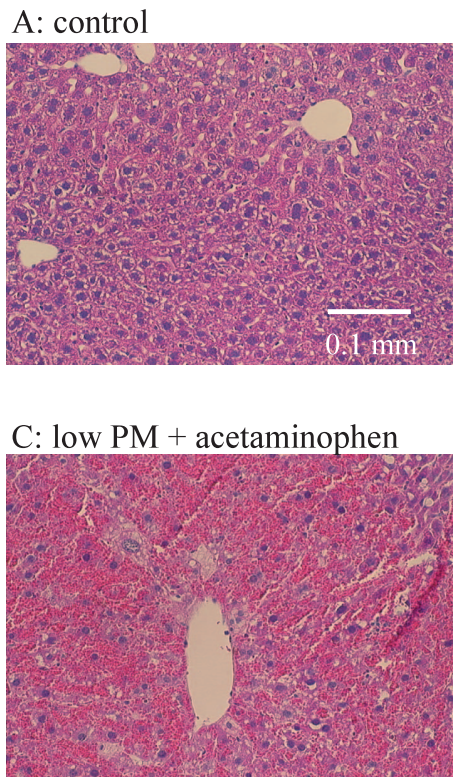

B: acetaminophen

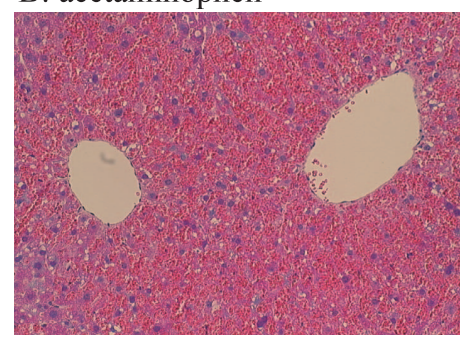

D: high PM + acetaminophen

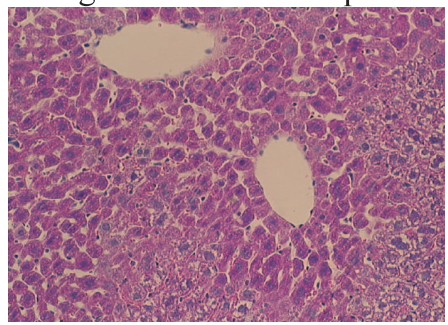

Fig. 4. Histopathological Observations of Liver Tissue after Subchronic PM Extracts Administration

Mice were orally pretreated with hot-water PM extracts (lower dose: $20 \mathrm{mg} / 0.2 \mathrm{ml} / \mathrm{mouse}$, higher dose: $340 \mathrm{mg} / 0.2 \mathrm{ml} / \mathrm{mouse}$ ) twice a day for 10 consecutive days, while control animals were similarly treated with distilled water $(2 \times 0.2 \mathrm{ml}$ per day). On day (final) 10 , acetaminophen (500 mg/kg) was injected intraperitoneally in mice $2 \mathrm{hr}$ after the last oral administration of PM extracts. Liver tissue was removed from mice $(n=3$ in each group) under ether anesthesia $4 \mathrm{hr}$ after acetaminophen treatment.

certain unreliable PM products or due to different preparation/isolation methods or some other causes.

The present hot-water-extracted PM not only prevented cell damage in serum-free culture media but also significantly attenuated acetaminopheninduced hepatotoxicity in the cultured hepatocytes. The significant preventive effect of hotwater-extracted PM in vivo was also observed on the acetaminophen-induced hepatotoxicity, however, only when extremely high dosage of PM extract $(c a ., 20 \mathrm{~g} / \mathrm{kg}$ ) was administered. In other words, the recommended dose of commercial PM products would not have significant benefit effect on hepatic failure. Acetaminophen was employed to induce hepatotoxicity in the present study because acetaminophen overdose induces fatal hepatic toxicities such as hepatic centrilobular necrosis. ${ }^{16)}$ Acetaminophen-induced hepatotoxicity involves free radical species, such as $N$-acetyl- $p$ benzoquinoimine, which behave as highly reactive metabolites strongly bound to proteins. ${ }^{17,18)}$ As such, the PM extract might have attenuated acetaminophen-induced hepatotoxicity via the antioxidation mechanism. In fact, anthraquinone, which is one of the PM components, exhibits antioxidative properties that enhance the hepatic mitochondrial glutathione status. ${ }^{13)}$ Previous re- ports ${ }^{13,19)}$ have indicated that the PM extract, which has been extracted by ethyl acetate, attenuates $\mathrm{CCl}_{4}$-induced hepatotoxicity in mice. PM extracts isolated by organic solvents show higher antioxidant activity. ${ }^{19)}$ Overall, our results in this study indicated that the hot-water-extracted PM, which is the conventional and popular PM preparation for consumption, exhibited non-injurious and limited beneficial effects on the liver function.

In conclusion, the hot-water-extracted PM in the present study showed protective effects against acetaminophen-induced toxicity in primarycultured hepatocytes, and subchronic (10-day) daily intake of the PM extract did not induce any hepatotoxicity per se. In fact, attenuation of acetaminophen-induced hepatotoxicity was established with our PM extract pretreatment, albeit the in vivo beneficial effect was obtained by the extremely high dosing.

Acknowledgements We wish to express our cordial thanks to Professor Katsuhiro Ogawa (Department of Pathology, Asahikawa Medical College) and Dr. Ko-ichi Yuki (Department of Pharmacology, Asahikawa Medical College) for their important suggestions. 


\section{REFERENCES}

1) Park, G. J., Mann, S. P. and Ngu, M. C. (2001) Acute hepatitis induced by Shou-Wu-Pian, a herbal product derived from Polygonum multiflorum. J. Gastroenterol. Hepatol., 16, 115-117.

2) But, P. P., Tomlinson, B. and Lee, K. L. (1996) Hepatitis related to the Chinese medicine Shou-wupian manufactured from Polygonum multiflorum. Vet. Hum. Toxicol., 38, 280-282.

3) Battinelli, L., Daniele, D., Mazzanti, G., Mastroianni, C. M., Lichtner, M., Coletta, S. and Costantini, S. (2004) New case of acute hepatitis following the consumption of Shou Wu Pian, a chinese herbal product derived from Polygonum multiflorum. Ann. Intern. Med., 140, 589-590.

4) Laird, A. R., Ramchandani, N., deGoma, E. M., Avula, B., Khan, I. A. and Gesundheit, N. (2008) Acute hepatitis associated with the use of an herval supplement (Polygonum Multiflorum) mimicking iron-overload syndrome. J. Clin. Gastroenterol., 42, 861-862.

5) Larry, D., Vial, T., Pauwels, A., Castot, A., Biour, M., David, M. and Michel, H. (1992) Hepatitis after germander (Teurium chamaedrys) administration: another instance of herbal medicine hepatotoxicity. Ann. Intern. Med., 117, 129-132.

6) MacGregor, F. B., Abernethy, V. E., Dahabra, S., Cobden, I. and Hayes, P. C. (1989) Hepatotoxicity of herbal remedies. BMJ, 299, 1156-1157.

7) Nadir, A., Agrawal, S., King, P. D. and Marshall, J. B. (1996) Acute hepatitis associated with the use of a Chinese herbal product, Ma-huang. Am. J. Gastroenterol., 91, 1436-1438.

8) Medicines and Healthcare Products Regulatory Agency (2006) Polygonum multiflorum and liver reactions, http://www.mhra.gov.uk/Howweregulate/ Medicines/Herbalandhomoeopathicmedicines/Herbalmedicines/HerbalSafetyNews/Currentsafetyissues/CON2023590

9) National Institute of Health Sciences (2006) Polygonum multiflorum and liver reactions, http:// www.nihs.go.jp/hse/food-info/foodinfonews/2006/ foodinfo200610.pdf.
10) Kubo, M., Matsuda, H., Fukui, M. and Nakai, Y. (1988) Development studies of cuticle drugs from natural resources. I. Effects of crude drug extracts on hair growth in mice. Yakugaku Zasshi, 108, 971978.

11) Wang, R., Tang, Y., Feng, B., Ye, C., Fang, L., Zhang, L. and Li, L. (2007) Changes in hippocampal synapses and learning-memory abilities in ageincreasing rats and effects of tetrahydroxystilbene glucoside in aged rats. Neuroscience, 149, 739-746.

12) Um, M. Y., Choi, W. H., Aan, J. Y., Kim, S. R. and Ha, T. Y. (2006) Protective effect of Polygonum multiflorum thumb on amyloid $\beta$-peptide $25-35$ induced cognitive deficits in mice. J. Ethnopharmacol., 104, 144-148.

13) Chiu, P. Y., Mak, D. H., Poon, M. K. and Ko, K. M. (2002) In vivo antioxidant action of a lignan-enriched extract of Schisandra fruit and an anthraquinone-containing extract of Polygonum root in comparison with Schisandrin B and emodin. Planta Med., 68, 951-956.

14) Moldeus, P., Hogberg, J. and Orrenius, S. (1978) Isolation and use of liver cells. Methods Enzymol., 52, 60-71.

15) Kubota, T., Fujisaki, K., Itoh, Y., Yano, T., Sendo, T. and Ohishi, R. (2004) Apoptotic injury in cultured hepatocytes induced by HMG-CoA reductase inhibitors. Biochem. Pharmacol., 67, 2175-2186.

16) Lee, W. M. (2003) Drug-induced hapatotoxicity. $N$. Engl. J. Med., 349, 474-485.

17) James, L. P., Mayeux, P. R. and Hinson, J. A. (2003) Acetaminophen-induced hepatotoxicity. Drug Metab. Dispos., 31, 1499-1506.

18) Reid, A. B., Kurten, R. C., McCullough, S. S., Brock, R. W. and Hinson, J. A. (2005) Mechanisms of acetaminophen-induced hepatotoxicity: role of oxidative stress and mitochondrial permeability transition in freshly isolated mouse hepatocytes. J. Pharmacol. Exp. Ther., 312, 509-516.

19) Ip, S. P., Tse, A. S. M., Poon, M. K. T. and Ko, K. M. (1997) Antioxidant activities of Polygonum multiflorum thumb., in vivo and in vitro. Phytotherapy Research, 11, 42-44. 